\title{
The Prevalence of Chlorpropamide Alcohol Flushing in Non-Insulin Dependent Diabetics
}

Dear Sir,

Leslie and Pyke have suggested that the chlorpropamide alcohol flush is a dominantly inherited trait in non-insulin dependent diabetics which is associated with a low prevalence of severe retinopathy $[1,2]$,

Köbberling and his colleagues have recently been unable to confirm these observations [3]. They found that the chlorpropamide alcohol flush was not specific for non-insulin dependent diabetics and they were unable to find any differences in the distribution of the chlorpropamide alcohol flush in diabetics with or without a family history of the disease.

We have performed the chlorpropamide alcohol flush test in 108 patients using $40 \mathrm{ml}$ of sherry $12 \mathrm{~h}$ after $250 \mathrm{mg}$ of chlorpropamide. The presence of a chlorpropamide alcohol flush was judged using facial temperature measurement, the feeling of a facial warmth by the patient or the appearance of a facial flush. The presence or absence of retinopathy was made following an examination through dilated pupils by an ophthalmologist who was unaware of the chlorpropamide alcohol flush status.

Table 1. The prevalence of chlorpropamide alcohol flushing in non-insulin dependent diabetics

\begin{tabular}{lcc}
\hline & \multicolumn{2}{l}{$\begin{array}{l}\text { Chlorpropamide alcohol } \\
\text { flush }\end{array}$} \\
\cline { 2 - 3 } & Positive & Negative \\
\hline No. (\%) & $35(33 \%)$ & $73(67 \%)$ \\
$\begin{array}{l}\text { Female } \\
\text { Family history }\end{array}$ & $26(74 \%)$ & $30(41 \%)$ \\
$\begin{array}{l}\text { Years of diabetes (mean } \pm \text { SEM) } \\
\text { Retinopathy }\end{array}$ & $6.5 \pm 0.8$ & $7.4 \pm 0.7$ \\
$\begin{array}{l}\text { Negative } \\
\text { Less than five lesions }\end{array}$ & $19(61 \%)$ & $43(70 \%)$ \\
$\begin{array}{l}\text { More than five lesions without } \\
\text { significant loss of visual acuity }\end{array}$ & $4(12 \%)$ & $2(3 \%)$ \\
$\begin{array}{l}\text { More than five lesions with } \\
\text { significant loss (more than } 50 \%)\end{array}$ & & \\
of visual acuity & $3(8 \%)$ & $3(5 \%)$ \\
\hline
\end{tabular}

A chlorpropamide alcohol flush occurred in 35 (33\%) of noninsulin dependent diabetics (Table 1). A positive test was obtained in $43 \%$ of the patients exhibiting a chlorpropamide alcohol flush when sherry was given alone without the previous administration of chlorpropamide. There was no difference in the prevalence of a family history of diabetes or background retinopathy in the two groups. There was however a greater percentage of patients with more than five exudates and/or haemorrhage in the chlorpropamide alcohol flush-positive patients (Table 1). Interestingly, there was an increased number of females in the chlorpropamide alcohol flush-positive group $(p<0.025)$.

In our experiment the chlorpropamide alcohol flush test, therefore, is not very specific since a sizeable proportion of chlorpropamide alcohol flush-positive patients showed a positive response to alcohol alone. The prevalence of chlorpropamide alcohol flush positive tests was not increased in patients with a family history of diabetes nor did we find evidence that chlorpropamide alcohol flush-positive patients are protected against severe retinopathy.

Our conclusions therefore agree with Köbberling et al. [3] in that the chlorpropamide alcohol flush test is unsuitable for genetic counselling and should not be used for the prognostic labelling of non-insulin dependent diabetic patients.

\section{References}

1. Leslie RDG, Pyke DA (1978) Chlorpropamide alcohol flush: a dominantly inherited trait associated with diabetes. Br Med J II: 1519-1521

2. Leslie RDG, Barnett AH, Pyke DA (1979) Chlorpropamide alcohol flushing in diabetic retinopathy. Lancet I: 997-999

3. Kobberling $\mathbf{J}$, Bengsch $\mathbf{N}$, Bruggeboes $\mathrm{B}$, Schwarck $\mathrm{H}$, Tillil $\mathrm{H}$, Weber M (1980) The chlorpropamide alcohol flush. Diabetolom gia 19: $359-363$

Piero Micossi, MD

Diabetes Clinic

Third Medical Department

Ospedale Provinciale L. Sacco

via G.M. Grassi 74

I-20157 Milano

Italy

\section{Delayed Menarche as an Indicator of a Prediabetic State}

Dear Sir,

Bailey and Ahmed-Sorour [1] have recently demonstrated that normal ovarian endocrine function plays an important role in the long-term maintenance of glucose homeostasis. There are also reports that oestrogen increases the sensitivity of adipose tissue and skeletal muscle to the action of insulin [2]. This may explain why ovariectomy increases the incidence and severity of experimental diabetes in female animals [3].

These observations also may be relevant to certain clinical findings concerning ovarian function in diabetic women. We have found that the age of onset of menarche in 986 women in whom diabetes appeared after the age of 20 years occurred significantly later $(\mathrm{p}<0.01)$ than in 1952 non-diabetic subjects $(14.2 \pm 1.9$ versus $12.8 \pm 1.2$ years) [4]. The number of diabetic women who had menarche at or after the age of 15 years $(29 \%)$ was higher than that found in non-diabetic women $(6 \%)$ (Table 1). The reason for this is difficult to define and requires further investigation. Disturbances in prolactin secretion [5-7] or the secretion of ovarian hormones [1] could provide an explanation.

Our data suggest that when menarche is delayed after the age of 15 years, there may be a predisposition for diabetes. Such patients need periodic investigation. 